\title{
El Hábeas Data y su desarrollo en el Perú
}

Francisco J. Eguiguren P.

\section{Aspectos generales}

Al igual de lo que ha venido sucediendo en diversos países, la incorporación del Hábeas Data al ordenamiento constitucional peruano es un hecho particularmente reciente y novedoso. Es en la Carta de 1993 (vigente desde el 31 de diciembre de dicho año) donde se estableció, en su artículo $200^{\circ}$, inc. 3 , dentro del Título que regula las «Garantías Constitucionales, la "Acción de Hábeas Data" como el instrumento para la protección de los siguientes derechos:

- a solicitar y obtener información de entidades públicas (Art. 2º, inc. 5);

- a que los servicios informáticos -públicos o privados- no suministren informaciones que afecten la intimidad personal y familiar (Art. $2^{\circ}$, inc. 6);

- al honor y a la buena reputación, a la intimidad personal y familiar, a la voz y la imagen propias, a rectificar las afirmaciones inexactas o agraviantes difundidas por un medio de comunicación social (Art. $2^{\circ}$, inc. 7 ).

Si nos atenemos a su denominación, el Hábeas Data conjuga una curiosa mixtura: de un lado, el vocablo "hábeas», que evoca al clásico Hábeas Corpus; $y$, de otro lado, la expresión "data», con su significado de información o datos, que refiere al vertiginoso desarrollo tecnológico reciente. El Hábeas Data parece surgir pues como intento de actualizar o extender el elenco de procesos constitucionales, para responder 
a las nuevas situaciones y realidades. Es decir que, en su traducción literal, el Hábeas Data supondría algo así como «traer la información» o "conservar los datos" ${ }^{1}$.

Buscando definir sus alcances y contenido más completos ${ }^{2}$, el Hábeas Data debe brindar a la persona afectada protección y mecanismos para obtener:

a) Acceso a información de su interés o a conocer datos sobre su persona que se encuentran en archivos o registros.

b) Actualización de informaciones o datos personales contenidos en archivos o registros.

c) Rectificación de informaciones o datos inexactos.

d) Exclusión o supresión de "datos sensibles" que, por su carácter personal o privado, no deben ser objeto de almacenamiento o registro a fin de salvaguardar la intimidad personal o la eventual no discriminación.

e) Confidencialidad de informaciones o datos personales que, por su carácter reservado, no debe permitirse su difusión a terceros (secreto tributario, bancario o médico).

Atendiendo a las consideraciones expuestas, cabe señalar que la regulación constitucional del Hábeas Data en el Perú mereció -casi desde un principio- severas críticas de autorizadas voces de la doctrina nacional. Así, García Belaunde ${ }^{3}$ considera una desnaturalización del Hábeas Data su extensión al derecho de rectificación, a la par de una peligrosa proclividad hacia la eventual censura de los medios de comunicación. Debe destacarse que similar preocupación fue asumida por los principales órganos de información y por entidades representativas del quehacer periodístico, generando una clara presión que llevó al propio oficialismo parlamentario a realizar una reforma constitucional que condujo a la supresión del Hábeas Data en dicho ámbito.

1 Cf. Ekmekdjian, Miguel Angel y Calógero Pizzolo: Hábeas Data. El derecho a la intimidad frente a la revolución informática. Depalma; Buenos Aires, 1996; p. 1.

2 Cf. Néstor Pedro Sagüés: «Hábeas Data: su desarrollo constitucional»; en, Lecturas Constitucionales Andinas, No 3; Comisión Andina de Juristas; Lima, 1994, pp. 90-92.

3 Cf. Domingo García Belaunde: “Garantías Constitucionales en la Constitución Peruana de 1993"; en, La Constitución de 1993; análisis y comentarios; serie Lecturas sobre Temas Constitucionales No 10; Comisión Andina de Juristas; Lima, 1994; pp. 259-260. 
A su vez, Abad Yupanqui ${ }^{4}$ considera que -en última instancia- la inclusión de este proceso constitucional especializado puede resultar innecesaria, pues similar protección ya era factible a través del Amparo; igualmente cuestiona el carácter tan amplio que se confiere a este instituto, al hacerlo extensivo a la rectificación de informaciones y a afectaciones de ciertos derechos personales a través de medios de comunicación social.

Por mi parte, además de haber compartido plenamente tales observaciones, quisiera adelantar -aunque pudiera parecer esta afirmación contradictoria- que no obstante la inadecuada extensión o ampliación del Hábeas Data para la protección de ciertos derechos afectados a través de los medios de comunicación social, sus alcances resultan claramente insuficientes o restringidos cuando regula la materia que le es -en estricto- genuinamente propia, es decir, la protección frente a informaciones o datos almacenados en archivos, registros o bancos informáticos. Paradójicamente pues, la regulación del Hábeas Data en la Constitución Peruana "peca» doblemente, en unos casos por excederse y, en otros, por omisiones o carencias.

\section{Desarrollo del Hábeas Data en la experiencia comparada}

Siendo que el Hábeas Data ha aparecido para la protección de ciertos derechos con relación a la libertad informática, sus antecedentes genéricos básicos podemos remontarlos a los intentos por preservar esferas personales de injerencias o perturbaciones externas no deseadas, a fin de garantizar la privacidad o intimidad personal. De allí se evolucionaría luego hasta llegar a la protección frente a los riesgos del almacenamiento, registro y utilización informatizada de datos relacionados con la intimidad personal o temas sensibles.

Conforme señalan Ekmekdjian y Pizzolo ${ }^{5}$, el desarrollo conceptual del derecho a la intimidad personal o right of privacy, tiene lugar en la

4 Cf. Samuel Abad Yupanqui: «Hábeas Data y conflicto entre órganos constitucionales"; en, Lecturas sobre Temas Constitucionales 10: Comisión Andina de Juristas; Lima, $1994 ;$ p. 268.

5 Op. cit; p. 8. En esta obra se puede encontrar una breve e interesante reseña de la evolución del derecho a la intimidad o privacidad en Estados Unidos y Gran Bretaña. 
experiencia de los Estados Unidos y en el Reino Unido, desde finales del siglo pasado. Un punto crucial en este itinerario fue la definición del derecho a la privacidad como the right to be let alone, es decir, el "derecho a ser dejado en soledad" (sin ser molestado o perturbado) elaborada por el juez Cooley; este concepto fue desarrollado por los juristas norteamericanos Warren y Brandeis, buscando proteger a la persona frente a datos o actos de índole personal, que se ponen en conocimiento del público o de terceros sin el consentimiento del afectado.

Tiempo después, aproximadamente desde 1960 y como reacción al vertiginoso desarrollo tecnológico que se traduce en nuevos sistemas informáticos, tanto en los Estados Unidos como en Gran Bretaña se empiezan a promover proyectos legislativos que, dando un nuevo giro o extensión al concepto de derecho a la privacidad, se refieren a la protección de la libertad y esfera personal frente a posibles excesos del registro informatizado o difusión de datos e informaciones vinculadas a aspectos reservados o íntimos.

Se llegó así, finalmente, a la Privacy Act norteamericana del 31 de diciembre de 1974, a la Data Protection Act británica de 1984, y a la Ley Orgánica No 5/1992 española, denominada «Regulación del tratamiento automatizado de datos".

En el nivel de los textos constitucionales, la Carta de Portugal de 1976 estableció, en su Art. 35\%, el derecho del ciudadano a: 1) Conocer las informaciones que le conciernen almacenadas en archivos, su finalidad y la posibilidad de rectificarlas o actualizarlas; 2) a que la información no sea utilizada para el tratamiento de datos «sensibles", referentes a convicciones políticas, religiosas o a asuntos de la vida privada, salvo que se trate de datos no identificables personalmente, con fines meramente estadísticos; 3 ) a que no se atribuya a los ciudadanos un número nacional único de identificación.

La Constitución Española de 1978 estableció, en su Art. 18.4, que "la ley limitará el uso de la informática para garantizar el honor y la intimidad personal y familiar de los ciudadanos y el pleno ejercicio de sus derechos". A su vez, en su Art. 105 ${ }^{\circ}$, b), asegura "el acceso de los ciudadanos a los archivos y registros administrativos, salvo en lo que afecte a la seguridad y defensa del Estado, la averiguación de los delitos y la intimidad de la persona». 
En el ámbito latinoamericano, fue la constitución brasileña de 1988, en su Art. $5^{\circ}$, inc. LXXII, la primera en abordar estos temas, pero sobre todo- también la primera en «bautizar» constitucionalmente al instituto del Hábeas Data ${ }^{6}$. Dicha norma dispone que: "Se concederá Hábeas Data: a) para asegurar el conocimiento de informaciones relativas a la persona de quien lo pide, que consten en registros o bancos de datos de entidades gubernamentales o de carácter público; b) para la rectificación de datos, cuando no se prefiera hacerlo en proceso reservado judicial o administrativo".

La constitución colombiana de 1991, ha establecido en su Art. $15^{\circ}$ que todas las personas tienen derecho a la intimidad personal y familiar y a su buen nombre, con la obligación del Estado de respetarlos y hacerlos respetar. Agrega luego: «De igual modo, tienen derecho a conocer, actualizar y rectificar las informaciones que se hayan recogido sobre ellas en bancos de datos y en archivos de entidades públicas y privadas. En la recolección, tratamiento y circulación de datos se respetarán la libertad y demás garantías consagradas en la Constitución».

A su turno, la Constitución del Paraguay de 1992, en su Art. 135, establece expresamente el Hábeas Data y dispone: «Toda persona podrá acceder a la información y a los datos que sobre sí misma o sobre sus bienes obren en registros oficiales o privados de carácter público, así como conocer el uso que se haga de los mismos y de su finalidad. Podrá solicitar ante el magistrado competente la actualización, la rectificación o la destrucción de aquellos, si fuesen erróneos o afectaren ilegítimamente sus derechos".

Como acertadamente señala Sagüés? ${ }^{7}$ la novedad principal de la norma paraguaya (por lo demás bastante completa en su regulación del Hábeas Data) radica en que no sólo comprende dentro de la protección de este instituto los consabidos derechos personales como privacidad, no discriminación, reserva sobre convicciones políticas o religiosas; sino también derechos personales de índole patrimonial, referidos a información o datos sobre bienes.

Más recientemente, la constitución argentina -con la reforma aprobada en 1994- regula expresamente en el Art. $43^{\circ}$ el Hábeas Data,

6 Cf. José Afonso Da Silva: Curso de Direito Constitucional Positivo; Editora Revista dos Tribunais, 1991; pp. 390-393.

7 Cf. Néstor Pedro Sagüés: Op. cit; p. 96. 
estableciendo que "Toda persona puede interponer esta acción para tomar conocimiento de los datos a ella referidos y de su finalidad, que consten en registros o bancos de datos públicos, o los privados destinados a proveer informes, y en caso de falsedad o discriminación, para exigir la supresión, rectificación, confidencialidad o actualización de aquéllos. No podrá afectarse el secreto de las fuentes de información periodística".

En definitiva, estos desarrollos doctrinarios y normativos fueron configurando un nuevo término y una suerte de derecho autónomo conocido como libertad informática, un derecho que «tiene por objeto garantizar la facultad de las personas para conocer y acceder a la información que les concierne, archivada en bancos de datos. Esto es el Hábeas Data: un instrumento para controlar la calidad de ellos, corregir o cancelar los datos inexactos o indebidamente procesados, y disponer sobre su posible transmisión $»^{8}$.

Siguiendo la doctrina sentada por el Tribunal Constitucional Alemán, puede hablarse de un derecho a la autodeterminación informativa ${ }^{9}$, consistente en la facultad de disponer sobre la revelación y utilización de los datos personales, que abarca todas las etapas de la elaboración y uso de datos por medios informáticos, es decir, su almacenamiento, registro, calificación, modificación, transmisión y difusión.

Una atingencia fundamental que cabe formular, luego de este breve recuento de la evolución de la institución del Hábeas Data, es que en rigor se aprecia una significativa confusión conceptual sobre su naturaleza. Así, en algunas constituciones se le regula como una suerte de derecho autónomo (aspecto sustantivo) consistente en la denominada "autodeterminación informativa» o la protección frente a los posibles excesos del poder informático en bancos de datos, archivos o registros. Mientras que en otros casos, como el peruano, se define al Hábeas Data como una garantía o proceso constitucional especial (aspecto instrumental) destinado a la protección y defensa de los derechos específicos antes señalados.

8 Ekmekdjian y Pizzolo: Op. cit; p. 23.

9 Un interesante análisis de la evolución de este derecho puede encontrarse en la obra El derecho a la autodeterminación informativa, de Pablo Lucas Murillo; publicada por Tecnos dentro de la serie "Temas claves en la Constitución Española". 


\section{El Hábeas Data en la constitución peruana de 1993}

Entre las novedades que introdujo la vigente constitución peruana de 1993, se encuentra la recepción del instituto del Hábeas Data como garantía constitucional. Así, en el inciso 3 del Art. $200^{\circ}$ se establece: "La acción de Hábeas Data, que procede contra el hecho u omisión, por parte de cualquier autoridad, funcionario o persona, que vulnera o amenaza los derechos a que se refiere el artículo $2^{\circ}$, incisos 5,6, y 7 de la Constitución».

Independientemente de la discusión sobre la necesidad o conveniencia de establecer al Hábeas Data como una garantía constitucional específica, pues en verdad es una suerte de Amparo «especializado» para la protección de ciertos derechos, sobre todo ante los riesgos de excesos provenientes del poder informático, considero que su regulación constitucional en el Perú ha incurrido en serias deficiencias.

En unos casos, el error o defecto ha provenido, presumiblemente, de confusiones conceptuales, que han llevado a desnaturalizar los alcances y el ámbito de acción propios del Hábeas Data, al darle una extensión amplia y, ciertamente, excesiva, involucrando dentro de su cobertura la protección genérica ante cualquier afectación de los derechos al honor y la buena reputación, a la intimidad personal y familiar, como a la voz e imagen propias: igualmente su aplicación al derecho de rectificación a informaciones inexactas o agraviantes difundidas a través de medios de comunicación social (inciso 7).

En otros casos, paradójicamente, la deficiencia consiste en la regulación restrictiva o diminuta de las posibilidades de protección frente a posibles excesos en el registro y difusión de datos por parte de servicios informáticos, que puedan afectar la intimidad personal o familiar (inciso 6). Ante ello, la utilización del Hábeas Data, precisamente en el terreno que le es más propio, resulta seriamente limitada.

Siendo que el Hábeas Data ha sido establecido por nuestra Constitución como un remedio procesal destinado a proteger determinados derechos, estimo que la mejor manera de apreciar las referidas deficiencias en que ha incurrido su regulación es analizando el tratamiento y alcances dados por la Carta a estos derechos. 


\section{a) Solicitud de información de entidades públicas.}

El inciso 5 del artículo $2^{\circ}$ de la Constitución reconoce que toda persona tiene derecho:

"A solicitar sin expresión de causa la información que requiera y a recibirla de cualquier entidad pública, en el plazo legal, con el costo que suponga el pedido. Se exceptúan las informaciones que afectan la intimidad personal y las que expresamente se excluyan por ley o por razones de seguridad nacional.

El secreto bancario y la reserva tributaria pueden levantarse a pedido del juez, del Fiscal de la Nación, o de una comisión investigadora del Congreso con arreglo a ley y siempre que se refieran al caso investigado».

Se trata de un derecho general de acceso a información (a solicitarla y a recibirla) exigible a entidades públicas; debemos entender que se refiere a informaciones que tienen carácter público, por lo que se justifica la exclusión de aquélla que pueda afectar la intimidad personal o la seguridad nacional, al margen de lo imprecisa que pueda resultar la determinación de los aspectos incursos en esta última restricción. También parece razonable dejar a la ley la posibilidad de incluir algunos otros ámbitos excluidos del acceso público, como pueden ser ciertos secretos comerciales o industriales, o historias clínicas, por ejemplo.

Naturalmente, la incorporación de este derecho constitucional de acceso a la información disponible en entidades públicas resulta muy positiva y destacable; sobre todo porque permite a los ciudadanos mayores niveles de participación y reafirma la tesis de que en materia de informaciones vinculadas a entidades estatales, la regla debe ser la publicidad y el acceso público a éstas, con el consiguiente libre acceso y conocimiento por parte de los interesados, sin necesidad de expresar la causa que motiva el requerimiento y con la sola obligación de solventar el costo que demande la reproducción y entrega de dicha información.

Es correcto que para asegurar el ejercicio efectivo de este derecho de acceso a información pública se establezca su protección a través de un proceso constitucional, a utilizar si la autoridad o entidad involucrada incumple con la obligación de proporcionar la información solicitada 
o si se resiste a hacerlo alegando que se trata de aspectos sujetos a reserva y excluidos del acceso público. En cualquiera de ambos supuestos, la acción constitucional de garantía permitirá que el interesado acuda a los tribunales, ya sea para que éstos obliguen al emplazado a atender el requerimiento o determinen si la razón alegada para justificar su negativa tiene suficiente fundamento.

Lo que sí cabría preguntarse es si la aplicación del Hábeas Data para la protección de este derecho general de acceso a la información pública, resulta compatible con la naturaleza y alcances habituales propios de este instituto.

En rigor, creo que la constitución peruana introduce una novedad algo peculiar en este campo, pues -como hemos tenido ocasión de apreciar- en la experiencia comparada predominante el Hábeas Data es estatuido para proteger la intimidad personal y ciertos datos "sensibles" que pueden verse afectados por su registro o difusión a través de servicios informáticos o bancos de datos de acceso o consulta pública.

El precepto constitucional bajo comentario se vincula a un derecho genérico de acceso a datos o informaciones, lo que no resulta del todo extraño a la naturaleza del Hábeas Data. La diferencia o novedad radica, en este caso, en que se trata de información en general a cargo de entidades públicas, sin establecer ninguna conexión o condición que la refiera a información existente en bancos de datos o servicios informáticos; también en que el interés principal protegido no es el resguardo de la intimidad personal o de la privacidad.

En realidad, el derecho cautelado en esta norma corresponde a la libertad de acceso y conocimiento de la información pública, destinado a favorecer la mayor y mejor participación e información general de los ciudadanos, así como la transparencia de la actuación y gestión de las entidades gubernamentales.

En todo caso, si bien esta extensión del Hábeas Data a la protección del derecho referido se aparta de los cánones más ortodoxos y difundidos del instituto (por lo que podría ser objetado por cierta falta de coherencia o "pureza" conceptual) es verdad también que ello no ofrece mayores problemas o perjuicios que ameriten un severo cuestionamiento 


\section{b) Suministro de información por servicios informáticos.}

El inciso 6 del artículo $2^{\circ}$ de la Constitución establece que toda persona tiene derecho:

"A que los servicios informáticos, computarizados o no, públicos o privados, no suministren informaciones que afecten la intimidad personal y familiar».

Aquí si nos encontramos en el ámbito más propio y aceptado de aplicación del Hábeas Data, resultando muy positivo que la Constitución haya incorporado este derecho, buscando así otra forma de preservar y resguardar la intimidad personal y familiar.

Una primera atingencia importante es que, en este caso, el sujeto obligado o quien aparece con legitimidad pasiva para ser emplazado en el Hábeas Data, es un servicio informático, público o privado, es decir una entidad cuyo objeto está referido al archivo, sistematización y difusión de datos, con la finalidad de brindar un servicio informativo, de registro o de consulta destinado al público o a terceros.

En esta línea, quedarían excluídos de los alcances de esta norma las informaciones almacenadas o elaboradas por personas particulares (tales como periodistas o investigadores) que para realizar su trabajo requieren disponer de ciertos datos, pero cuyo objeto o finalidad es el uso privado. Igualmente considero que podrían quedar excluídos los bancos de datos de entidades privadas cuya información no está destinada al acceso público ni a ser comunicados o difundidos a terceros.

En todo caso, considero que la utilización del término "servicios informáticos», resulta inconveniente y se presta a equívocos. Y es que no debemos entender que se refiere únicamente a las instituciones públicas o empresas privadas que prestan o venden servicios informáticos a terceros, pues con tal criterio, los registros, archivos o bancos de datos de ciertas dependencias públicas que sirven de apoyo al accionar de su institución (Ministerio del Interior, Dirección de Migraciones, Policía) y cuya finalidad no es ofrecer el servicio de suministro de datos, podrían pretender quedar fuera del alcance de la norma constitucional, lo que -ciertamente- burlaría y desnaturalizaría tanto su propósito como su eficacia.

En suma, por encima del contenido literal del término, debemos interpretar que "servicios informáticos» se refiere e involucra a los ban- 
cos de datos, archivos o registros que almacenan y suministran información.

Otro aspecto particularmente grave, es que el texto de este precepto constitucional se restrinja únicamente a prohibir que los servicios informáticos suministren datos o informaciones que puedan afectar la intimidad personal o familiar, dejando aparentemente fuera de la norma todos los otros aspectos que son típicos de este derecho a la autodeterminación informativa y a la protección del Hábeas Data. Ello revela una lamentable ignorancia y ligereza, pues si el constituyente recogió el Hábeas Data de otras experiencias, cuando menos debió hacerlo en forma completa e integral. Nótese que al momento de elaborarse la constitución peruana ya se encontraban vigentes, para no ir más lejos, las constituciones de Brasil y Paraguay, que regulan este instituto con notoria superioridad en calidad con respecto a nuestra Carta.

Una revisión (e interpretación) literal de la norma no incluye el derecho de la persona a acceder (conocer y recibir) a la información o datos que le conciernen y que se hayan registrados en el banco de datos; y sin ello, mal pueden ejercitarse los otros aspectos que suele involucrar este derecho y su protección mediante el Hábeas Data. Tampoco se podría solicitar y exigir la rectificación o actualización de datos inexactos o falsos, ni -mucho menos- la supresión de datos sensibles que afectan la intimidad personal o familiar.

En síntesis, esta norma constitucional se limitaría, si nos atenemos a su tenor literal, a proteger a la persona evitando que los servicios informáticos suministren datos o informaciones que afectan la intimidad personal, desatendiendo aparentemente todas las otras posibilidades de cobertura de este derecho. Incluso podría pretenderse dejar fuera de la prohibición la difusión de datos que, sin vulnerar la intimidad personal o familiar, pueden conllevar formas de discriminación o contribuir a ésta.

Considero pues muy lamentable el tratamiento dado por nuestra Constitución a este punto, que es el más propio y típico del ámbito de protección del Hábeas Data. Los riesgos de interpretaciones y aplicaciones restrictivas de esta norma pueden ser grandes, siendo de esperar que tal criterio no sea adoptado ni propiciado por la legislación de desarrollo constirucional ni por la jurisprudencia.

Por mi parte creo que una adecuada comprensión de la norma, en aras de efectuar la integración de este derecho y el resguardo de su contenido esencial, exigiría aceptar también la procedencia del Hábeas 
Data para conseguir conocer, actualizar, rectificar o suprimir datos personales almacenados en servicios informáticos. Y es que si la Constitución prohibe el suministro de ciertos datos o informaciones, con mayor razón cabría extender los alcances del derecho y del Hábeas Data a los otros supuestos complementarios, pues se trata de componentes básicos y mínimos del derecho a la autodeterminación informativa, que incluso comportan exigencias menos severas.

A mayor abundancia, no sería razonable que el Hábeas Data pueda utilizarse para impedir el suministro o difusión de datos personales sensibles, y -a la vez- excluirlo de eficacia para conocer el contenido de la información que sobre la propia persona obra en el banco de datos, máxime si la Carta (en otra norma) concede un derecho genérico de acceso a información pública. $\mathrm{O}$ impedir que por esta vía se actualice o rectifique datos personales inexactos o falsos, cuando la Constitución reconoce un derecho de rectificación a ejercitar ante los medios de comunicación que difundan informaciones inexactas. $O$ que se inhabilite al Hábeas Data para lograr la supresión de datos sensibles o informaciones indebidamente registradas, cuando su sola tenencia en el banco de datos del servicio informático conlleva ya una perturbación o injerencia no consentidas en la intimidad personal y la privacidad; o si la continuidad del dato en el registro puede ocasionar alguna forma de discriminación contra la persona concernida.

c) Derechos al honor, buena reputación, intimidad personal y familiar, voz e imagen propias, y derecho de rectificación

El inciso 7 del artículo $2^{\circ}$ de la Constitución establece que toda persona tiene derecho:

"Al honor y la buena reputación, a la intimidad personal y familiar, así como a la voz y a la imagen propias.

Toda persona afectada por informaciones inexactas o agraviada en cualquier medio de comunicación social tiene derecho a que éste se rectifique en forma gratuita, inmediata y proporcional, sin perjuicio de las responsabilidades de ley".

Como ya adelantamos, la extensión del Hábeas Data a la protección de los derechos al honor y la buena reputación, la intimidad personal 
y familiar, la voz y la imagen propias, y al derecho de rectificación en los medios de comunicación social, configuró un gravísimo exceso del constituyente del 93. Siendo que conceptualmente el Hábeas Data busca proteger la intimidad personal y la privacidad frente a posibles abusos del poder informático, mediante el registro y difusión de datos sensibles, la aplicación genérica de este remedio procesal constitucional a cualquier clase de afectación de la intimidad y, lo más serio, la inclusión de otro conjunto de derechos que podrían verse afectados a través de los medios de comunicación, revela una muy acusada falta de conocimiento y de idoneidad técnica.

Si la extensión, anómala y desnaturalizada, del Hábeas Data a los derechos antes referidos no fue producto de una confusión, sino que obedeció a una decisión explícita -como sostienen algunos- el asunto puede resultar incluso más delicado. Y es que la intención sería impedir la difusión de datos o informaciones obtenidos a través de la investigación periodística, alegando la afectación de la buena reputación o intimidad de ciertos personajes públicos.

En cualquier caso, fueron tan unánimes y persistentes las críticas que los representantes de los medios de comunicación, del gremio periodístico como de la comunidad académica formularon a esta peligrosa desnaturalización del Hábeas Data, que la mayoría oficialista en el Congreso tuvo que hacerse eco de las mismas. Y así se apuró una reforma del texto constitucional, aprobada mediante Ley No 26470 (del 12 de junio de 1995) que excluyó al inciso 7 del Art. $2^{\circ}$ de la Carta de la aplicación del Hábeas Data, quedando tales derechos bajo la tutela de la acción de Amparo. Esta atinada corrección, nos releva de mayores comentarios al respecto.

\section{El funcionamiento del Hábeas Data}

\subsection{El procedimiento:}

La novedosa, aunque imprecisa, incorporación constitucional de la acción de Hábeas Data y la ausencia de una norma procesal que regule su aplicación, sumada a la falta de remisión al procedimiento que debía seguir su tramitación, generaron algunas dudas y confusiones en este campo. 
Al saberse que, a pesar de su denominación, el Hábeas Data es una suerte de "Amparo especializado", lo razonable era asumir que el procedimiento a aplicar -al menos transitoriamente- era el que corresponde al Amparo. Esta es, inclusive, la solución definitiva seguida en países como Brasil (Mandato de Seguridad), Colombia (Tutela) y Argentina. Sin embargo, se hizo necesario dictar la Ley No 26301 (del 3 de mayo de 1994) norma que tiene una expresa vocación transitoria, en tanto se dicte una nueva ley orgánica de garantías constitucionales que regule en detalle el Hábeas Data, y que resolvió algunos problemas o dudas de indole procedimental.

Dicha ley dispone que es competente para conocer del Hábeas Data el juez de primera instancia en lo Civil de turno, del domicilio del demandante o del demandado; si la afectación del derecho se origina en archivos judiciales, sean éstos jurisdiccionales, funcionales o administrativos, la acción se presentará ante la Sala Civil de turno de la Corte Superior respectiva, la que designará a un juez de primera instancia en lo Civil para efectos del trámite, pero correspondiendo el fallo a la Sala.

En realidad, se trata de una solución similar a la que rige en el proceso de Amparo; por lo demás, la comentada ley hace una remisión expresa a la aplicación procesal supletoria al Hábeas Data de las normas que regulan al referido proceso. La ley contiene también disposiciones relativas a la tramitación del Hábeas Data cuando se trate del ejercicio del derecho de rectificación o de acciones contra medios de comunicación social, que obviamente han quedado derogadas por la ulterior reforma constitucional que excluye a tales supuestos de la protección de dicha garantía.

Quizás el punto más cuestionable de la Ley No 26301, al margen de los vacíos producto de su carácter coyuntural y transitorio, está referido al tema de las vías previas. El Art. $5^{\circ}$, Inc. a) dispone que, además de las reglas y excepciones que rigen el agotamiento de las vías previas en el Amparo (Ley No 23506, artículos $27^{\circ}$ y $28^{\circ}$ ) para el ejercicio del Hábeas Data en los casos de solicitud de información pública o de oposición al suministro de información por servicios informáticos (incisos 5 y 6 del Art. $2^{\circ}$ de la Constitución) el afectado debe previamente haber formulado un requerimiento, por conducto notarial, con una antelación no menor de quince días calendario. 
Considero conceptualmente inapropiada esta equiparación del requerimiento notarial previo a la figura de la vía previa y su agotamiento, coincidiendo en este punto con las objeciones que también plantean Abad Yupanqui ${ }^{10}$ y Borea Odría ${ }^{11}$. Si bien el requerimiento antelado por conducto notarial tiene por finalidad dar la oportunidad al presunto agresor de corregir su conducta, evitándose así el recurso ulterior al Hábeas Data, ello dista mucho de asemejarse a la noción de vía previa en el Amparo, que supone la existencia de un típico procedimiento reglado, normalmente ante autoridad administrativa, lo que explica la exigencia de su agotamiento previo y también que se contemplen taxativamente excepciones a dicha regla.

\subsection{La jurisprudencia:}

Hasta la fecha la utilización concreta del proceso de Hábeas Data viene siendo más bien escasa, situación que -por lo demás- encuentra diversas explicaciones. De un lado, está el hecho de que esta acción de garantía protege específicamente sólo a dos derechos constitucionales, vinculados al acceso a información pública y al impedimento de suministro de informaciones o datos sensibles por parte de servicios informáticos. De otro lado, la relativa novedad de ambos derechos, y del propio instituto del Hábeas Data, determinan su insuficiente conocimiento y restringido uso práctico.

Cabe señalar que el primer caso de Hábeas Data fue promovido por el abogado Vladimir Paz de la Barra, contra los periodistas Nicolás Lúcar y Roxana Cueva, alegando la defensa de sus derechos al honor y reputación y el de rectificación. Sostenía el letrado que el informe periodístico difundido en un programa televisivo, el 30 de enero de 1994, lo vinculaba erróneamente como asesor del responsable de un conocido caso de estafa financiera en agravio de miles de ahorristas, así como de una operación fraudulenta de adquisición de bonos, dañando su prestigio profesional y personal. En la demanda se solicitaba la rectificación del medio informativo, el inicio de acción penal contra los emplazados y el pago de una reparación, así como que éstos se absten-

10 Op. cit; p. 12.

11 Cf. Alberto Borea Odría: Evolución de las Garantías Constitucionales; Grijley, Lima, 1996 ; pp. $481-484$. 
gan de futuras informaciones vinculándolo a dicho caso o al patrocinio jurídico del estafador.

Un aspecto peculiar de este primer caso de Hábeas Data fue que la acción se interpuso ante un juez penal (como corresponde en materia de Hábeas Corpus) no obstante que los derechos afectados venían siendo protegidos, hasta antes de la Carta del 93, a través del Amparo, que se ventila ante el juez civil. Fue por ello que el fallo del cuadragésimo sexto juzgado penal de Lima (de fecha 7 de febrero de 1994) se declaró inadmisible la acción, dado que -pese a no existir ley reglamentaria- el proceso de Hábeas Corpus no era equiparable por estar dedicado específicamente a la tutela de la libertad individual y derechos conexos, por lo que la vía penal, deliberadamente escogida por el actor, no resulta aplicable al Hábeas Data ni compatible con el debido proceso.

A su turno, el fallo de segunda instancia (del 28 de febrero de 1994) confirmó por mayoría la sentencia apelada, agregando como elemento desestimatorio el que el demandante no haya intentado previamente la rectificación de manera directa ante los emplazados. El voto de minoría sostuvo que, si bien no existía norma legal que determinara al juez natural competente, resultaba preferible encargar la tramitación y resolución del caso al juez penal que ya conocía del proceso, opinando por la revocación y modificación del fallo en ese sentido.

Finalmente la Corte Suprema, en fallo del 28 de marzo de 1994, consideró que ante la falta de norma procesal específica aplicable al Hábeas Data, debía recurrirse supletoriamente a la legislación de Hábeas Corpus y Amparo, siendo aplicable al caso el procedimiento de Amparo, por no tratarse de derechos vinculados a la libertad individual. En consecuencia, declaró nula la sentencia de segunda instancia e insubsistente la apelada, ordenando que la causa se remita al juez civil de primera instancia para su tramitación desde el inicio ${ }^{12}$.

Para entonces, al parecer el accionante ya no tuvo interés o necesidad de proseguir con el proceso, quedando éste en dicha situación. Poco después la referida Ley No 26301 vino a intentar corregir este tipo de incertidumbre procedimentales, siguiendo los principales criterios expuestos en la resolución de la Corte Suprema.

12 Los diferentes fallos citados, correspondientes al caso, están publicados en Autos \& Vistos: Comentarios jurisprudenciales; Colegio de Abogados de Lima y Gaceta Jurídica; eneto de 1996; pp. 41-53. 
Un caso muy importante fue el promovido por la Sociedad Peruana de Derecho Ambiental contra el Ministerio de Energía y Minas, ante la negativa de éste a entregarle información sobre la cancha de relaves de la empresa minera aurífera Retama (MARSA). La recurrente, una asociación civil sin fines de lucro dedicada a la defensa y promoción del medio ambiente, alegaba tener conocimiento de un grave caso de daño ambiental causado por la empresa, que ocasionó contaminación de aguas y destrucción de bosques y cultivos, por lo que solicitaba la información del expediente técnico de otorgamiento de la concesión minera y de la autorización de la referida cancha de relaves.

La Fiscal Suprema en lo Contencioso-Administrativo dictaminó por la declaración de NO HABER NULIDAD del fallo de segunda instancia que, revocando la sentencia apelada y reformándola, declaró fundada la acción de Hábeas Data interpuesta. A su turno, la Sala de Derecho Constitucional y Social de la Corte Suprema, mediante fallo del 19-6-96, compartió similar criterio y declaró fundada la demanda. Expresó la Sala que la accionante estaba ejerciendo el derecho de acceso a información pública que le confería el inciso 5 del Art. $2^{\circ}$ de la Constitución, estando incluso legitimada por el Código del Medio Ambiente para obtener información sobre actividades que puedan afectar la salud de las personas, la conservación del medio ambiente o la integridad de los recursos naturales. En consecuencia, ordenó que el Ministerio demandado proporcione la información solicitada por la entidad accionante ${ }^{13}$.

Otro caso importante, invocando el mismo inciso 5 del Art de la Constitución, fue el Hábeas Data interpuesto por la Asociación Civil «Labor», de Ilo, contra el Director General de Minería, solicitando se le proporcione los estudios de impacto ambiental presentados por la empresa minera Southern Perú Cooper Corporation para la instalación de una planta de ácido sulfúrico en la fundición de cobre que tiene en Ilo, así como de la resolución que aprueba la instalación de depósitos de dicho ácido en el casco urbano del referido puerto.

La Sala Especializada de Derecho Público de la Corte Superior de Lima declaró "fundada" esta acción, revocando el fallo apelado que había dispuesto, más bien, la «improcedencia», ordenando al Ministe-

13 Ver Exp. No 1658-95, publicado en el diario oficial El Peruano, "Jurisprudencia»; miércoles 4 de setiembre de 1996; p. 2297. 
rio la entrega de la información solicitada por la emplazada. El punto de mayor interés de este fallo, radica en que la Corte reitera que es a ésta a quién compete determinar si la información requerida se encuentra en alguna de las causales de exclusión establecidas por la Constitución o la ley. En tal sentido, sostiene que "...en todo caso, no corresponde ni a la Procuraduría Publica mencionada, ni a la Dirección General de Minería, calificar la solicitud de información requerida por la emplazante, como atentatoria de la seguridad o reserva de la empresa privada, sin que semejante calificación tenga el fundamento legal requerido, tanto más cuanto que, conforme a lo previsto por el artículo décimo primero del Decreto Legislativo No 603, Código del Medio Ambiente, los estudios de impacto ambiental se encuentran a disposición del público en general... ${ }^{14}$

El hecho que no se disponga de casos promovidos en relación a informaciones contenidas en banco de datos o servicios informáticos, producto de su aún incipiente desarrollo o difusión entre nosotros, no permite prever los criterios de interpretación que haya asumido, o pueda asumir, la judicatura en esta materia.

\section{A manera de conclusión}

Al margen de lo novedoso que ha resultado la incorporación constitucional del Hábeas Data, considero que su existencia como garantía o proceso constitucional carece de suficiente justificación, pues no pasa de ser una suerte de "Amparo especializado" para la defensa de ciertos derechos.

No resulta casual que en países como Brasil, Colombia o Argentina, el ejercicio del Hábeas Data se remita al procedimiento del Amparo (o su equivalente nacional) y que en el Perú la incipiente legislación de la materia no ofrezca ninguna peculiaridad sustancial que amerite la existencia de un proceso constitucional autónomo o diferente del Amparo. Ello nos convence de la conveniencia de efectuar la supresión del Hábeas Data del elenco de las garantías constitucionales.

14 Ver Exp. No 263-96, publicado en el diario oficial El Peruano, del sábado 28 de diciembre de 1996; p. 2698; repetida el domingo 29 de diciembre de 1996, pp. 2748-2749. 
Muy distinto es el caso si es que tendemos a entender la institución del Hábeas Data no como una garantía sino -más bien- como la denominación particular de un derecho específico, o de un conjunto de éstos, vinculados ya sea a la autodeterminación informativa (Art. $2^{\circ}$, Inc. 6) o al acceso a información de entidades públicas (Art. $2^{\circ}$, Inc. 5). Por ello encontramos muy positiva la presencia en el texto de la Carta de 1993 de dichos derechos.

Lo cuestionable es que, en el caso del inciso $6^{\circ}$, se haya regulado con inexcusable insuficiencia los alcances de dicho derecho y, consiguientemente, las posibilidades claras de utilización del Hábeas Data para lograr conocer, actualizar o rectificar datos almacenados en servicios informáticos, así como para suprimir del registro datos personales sensibles. Es de esperar que la ley o la jurisprudencia puedan suplir esta deficiencia y así asegurar el respeto al contenido esencial de este derecho y la eficacia del Hábeas Data.

También fue justificadamente cuestionada la extensión del Hábeas Data a la protección de los derechos al honor y buena reputación, intimidad personal y familiar, imagen y voz propias, y de rectificación en los medios de comunicación (inciso 7 del Art. $2^{\circ}$ de la Carta, pues desnaturalizaba seriamente este proceso. Es muy positivo que este error se haya corregido y superado, para lo cual fue necesario realizar una reforma del texto constitucional, excluyendo a dichos derechos de la tutela del Hábeas Data y devolviéndolos a la protección del Amparo.

Habrá que esperar también que una futura ley orgánica integral de desarrollo y regulación de las garantías constitucionales, brinde un completo y adecuado tratamiento al Hábeas Data, superando así los vacíos y limitaciones de la norma transitoria actualmente vigente. En todo caso, resulta muy poco consistente que al establecerse el requerimiento previo, por conducto notarial, como condición de procedencia para el ulterior ejercicio del Hábeas Data, se haya pretendido equiparar este paso con la existencia de una "vía previa" y la exigencia de su agotamiento, que rige en materia de Amparo.

Sólo resta aguardar que la utilización del Hábeas Data se incremente cada día y, lo más importante, que la jurisprudencia vaya plasmando criterios que garanticen su eficacia y completen los alcances de los derechos constitucionales involucrados. Ello será fundamental, y decisivo, para el futuro de este proceso constitucional, pues no debe olvidarse que su ejercicio supone -en no pocos casos- intentar afianzar la 
transparencia en la gestión e información de instituciones públicas, cuyo accionar ha gustado de privilegiar el secreto y la exclusión de acceso informativo al ciudadano. Asimismo, porque estará también de por medio frecuentes casos de enfrentamiento con poderosos intereses políticos y económicos, tanto de entidades gubernamentales como de grupos privados. 